\title{
The Thinking of the Interactive Communication Paths between the Ideological and Political Course Teachers Based on the Party Building Network Platform and the Students
}

\author{
Yingxia Liu ${ }^{1, a^{*}}$ and Huiqian Zhang ${ }^{1, b}$ \\ 524107003@qq.com \\ *the corresponding author
}

${ }^{1}$ Institute of Marxism, Dalian University, Dalian, Liaoning, 116622, China

Keywords: Colleges and universities; College students; Party building; Network Party building; Ideological and political course teacher; Interactive communication

\begin{abstract}
In the era of Internet, the ideological and political course teachers in colleges and universities should play a leading role. In addition to the heavy teaching and research tasks, based on the construction of student Party building network platform, they should interact with students in order to realize the purpose of cultivating students with multi-agent linkage. Based on the necessity of combining the Party building work of college students with the network platform construction, this paper analyzes the main problems in the network Party building work of college students, discusses the necessity and feasibility of the interactive communication between the students and the ideological and political course teachers through the network platform, and also puts forward some suggestions on improving the Party building work of college students, realizing the interaction between teachers and students and giving full play to the guiding role of ideological and political teachers.
\end{abstract}

\section{思政课教师基于党建网络平台与学生互动交流的}

\author{
路径思考 \\ 刘英侠 ${ }^{1}$ 张慧倩 $^{2}$ \\ 1. 大连大学 马克思主义学院教师 中国 辽宁 大连 116622 \\ 2. 大连大学 马克思主义学院在读研究生 中国 辽宁 大连 116622 \\ 524107003@qq.com
}

摘要: 互联网时代, 高校思政课教师也要发挥引导作用, 在繁重的教学科研任务之外, 基于学生党建网络平台建设, 与 学生进行互动交流, 以实现多主体联动培养学生之目的。文章从大学生党建工作与网络平台建设相结合的必要性出发, 分析 了高校大学生网络党建工作存在的主要问题，论述了思政课教师可以通过网络平台实现与学生互动交流的必要性和可行性， 并对进一步做好高校学生党建工作，实现师生互动，发挥思政课教师的引领作用提出了建议。

关键词：高校；大学生；党建；网络党建；思政课教师；互动交流

\section{1 引言}

2016 年底, 习近平总书记在全国高校思政工作会议上强调了新媒体对高校思政工作的重要作用，指出 “要运用新媒体新技术使工作活起来，推动思想政治工作传统优势同信息技术高度融合，增强时代感和吸 
引力” 1 , 这对高校思政工作提出了改革的方向。“高校基层组织建设非常重要, 大学生是最新鲜、最有 活力的群体, 是新增党员最重要的来源, 加强对大学生的价值观和理想信念教育, 提高他们对党的认同感 和归属感, 都与高校基层组织建设息息相关。2” 在党的十九大报告中还指出： “青年一代有理想、有本 领、有担当, 国家就有前途, 民族就有希望 3 ”, 大学校园是青年人集中的地方, 理应将媒体的作用充分 发挥好，使一代代青年勇做时代的弄潮儿。

\section{2 高校大学生网络党建工作的必要性}

\section{1 符合时代发展的需要}

当前社会, 网络发展的势头十分迅猛, 人们的生活、学习、教育等均与互联网建立起紧密的联系。在 各行各业推动 “互联网+” 发展的时期, 高校大学生党建工作也应该跟上创新变革的脚步, 探索出新渠道 以推动党建工作的开展。习近平同志也曾说过: “网络发展到哪里党建工作就要覆盖到哪里。”由此可见, 网络平台与党建工作的结合是时代发展、社会进步的必然要求, 也是传统党建工作的重大突破。

\section{2 符合大学生党员群体特殊性的需要}

2016 年《党建蓝皮书》中的统计数据显示: 至 2013 年底，全国学生党员共有 224.7 万人，占所有正 式党员总数的 $3 \%$, 并且学生群体是党员增速最快的一个部分, 无论是规模还是比重都比前些年有很大的提 高。这个数据表明, 中国共产党对年轻人的吸引力在不断扩大, 党的基层力量在日益强大。90后作为当代 大学生的主体, 亦是大学生党员的主体, 在信息技术大变革的背景下成长, 对互联网具有极佳的敏感性, 网络与他们的学习、生活息息相关。这在一定程度上为高校大学生党建和网络平台的结合打通了 “任督二 脉”，二者的结合刻不容缓。

\section{3 改善传统高校大学生党建工作的需要}

从目前的发展形式看，学生党员发展的力度在不断加大，学生党员队伍越来越壮大，大部分高校已经 开始重视将学生党建工作和思想政治教育工作紧密结合起来, 使学生党员和学生党支部的作用在校风、学 风建设以及和谐校园建设等方面得到了发挥。但是, 高校学生党建工作还存在一些薄弱环节, 如党建工作 宣传方式单一、影响力的覆盖范围面小等。因此, 深入分析当前高校学生党建工作存在的问题, 将网络与 党建完美结合对改善传统大学生党建工作有着重要的意义, 因为这种结合不仅能满足基数庞大的大学生积 极分子和党员接受红色宣传教育的需求, 更可以为高校学生党建工作提供一个高效便捷的平台, 使党建的 基础工作更有效率和质量。

\section{3 高校大学生网络党建工作存在的主要问题}

\section{1 学生党员的思想政治教育水平叒待提高}

作为党组织的重要组成部分, 大学生的素质需要不断提升, 只有接受党的先进性教育, 才能保证党的 后备军的质量, 即大学生不仅要保证日常的专业课学习, 还要与时俱进, 不断学习党的路线、方针、政策, 特别要了解实事政治，关心国家大事，增强主人翁意识，以先进的思想武装自己。

我们曾访谈过数十所高校的入党积极分子以及预备党员对于高校大学生网路党建发展情况的意见，经

\footnotetext{
1 申文杰.当前我国高校意识形态建设的现实性路径[J].高校马克思主义理论研究, 2016 (12).

2 胡浩. 习近平在全国高校思想政治工作会议上的重要讲话反响热烈[N].中国网-新闻中心, 2016-12-10.

http://www.china.com.cn/news/2016-12/10/content_39889087.htm.

3 决胜全面建成小康社会 夺取新时代中国特色社会主义伟大胜利[N].人民日报，2017-10-19.
} 
过分析汇总, 得出大学生党员的思想政治水平函待提高的结论。即使以严格的标准, 如学习成绩在年级前 百分之十五、担任学生干部并对学院有一定的贡献等选拔出来的优秀大学生党员也仍存在着政治素养薄弱 的问题, 尤其是在全面从严治党的前提下, 各高校的廉洁教育工作更应该被提到重要的位置来对待。

究其根本, 原因有二, 一是大学生对自己的入党动机不明确, 缺乏足够的党性锤炼, 不能主动自觉参 与政治学习, 主体素质不能适应党内民主的发展, 此为最内在的因素, 需要党组织进行适当引导, 学生自 身提高认识; 二是一些高校学生党建教育工作的内容枯燥, 形式单一, 创新性弱, 缺乏生机与活力, 在某 种程度上难以将党组织的精神与知识有效地传达给学生党员, 生硬的灌输很难起到好的作用, 影响学生党 员参与活动的积极性、主动性以及创造性的充分发挥。

\section{2 党建活动吸引力低}

党建活动作为学生党建宣传与教育的重要组成部分, 对大学生政治思想水平的提升有着促进作用。传 统党建活动有宣传板报、讲授式党课、定期写思想汇报、找辅导员和培养人谈话、集中学习党中央下发的 文件、在特殊节日（如建党节、学雷锋日等）组织相关活动、参观博物馆、展览馆等等。

这些活动的主要缺点有：一是宣传的覆盖面小, 宣传效果难以衡量, 受众人群的局限性决定了党建工 作难以普及, 完全发挥其作用, 即使想扩大宣传范围, 也受到时间、地点、人力和物力的限制; 二是宣传 内容通常以文字或单一的讲授为主, 缺乏图片、视频资料等表现形式, 生动性不足, 吸引力低, 无法引起 学生关注, 在造成了宣传资源浪费的同时, 也在无形中流失了部分学生党员。

\section{3 学生党建网络平台作用发挥的少}

从调研情况看, 好多高校都有网络党建的设计规划, 也都相应建立了官网, 设计了一些栏目, 但是栏 目中内容的更新速度慢, 使用率不高, 与学生在官网上的互动少。当前, 有一些辅导员和思政课教师充分 利用起了手机的微信群和 $\mathrm{QQ}$ 群, 这两种联系方式比较直接快速, 但是存在一个问题就是难以保留更多的 记录, 一些通知、链接会被聊天记录冲掉, 过后难以找到, 而且, 没有官网平台显得庄重、正式, 一些不 够积极主动的学生或者是不太习惯于用手机的学生对这种党建工作方式的接受程度有待提升。

\section{4 思政课教师参与学生网络党建的积极性低}

高校意识形态领域的工作应该是全员齐上阵的系统工作, 不仅包括辅导员, 还应该包括各种任课教师, 但目前的情况不容乐观, 不仅专业课教师对这个工作关注的少, 即使是思政课教师也通常会把学生党员的 思想教育工作视作辅导员的工作, 参与的积极性低, 难以与辅导员相互配合, 入党积极分子在思政课上的 获得感不高, 思政课教师也更难以加入到网络党建平台的设计及运行中去。这种情况不仅对发展学生党员 的质量没有帮助, 而且对构建高校思政课的话语体系也没有发挥出作用。在高校思政课提升教学质量、创 新教学方法的时代要求下, 在互联网技术高速发展的前提下, 思政课教师应该走出书本, 多与学生互动交 流, 了解其思想动态, 掌握意识形态发展情况, 有针对性地对学生开展思想教育, 与辅导员密切配合完成 学生网络党建工作。

\section{4 思政课教师基于网络党建平台与大学生实现互动交流的几点建议}

基于上述现状, 思政课教师应该与辅导员密切配合, 充分发挥网络党建平台的作用, 将高校党建工作 推向现代化和网络化, 提升学生对党的认识和了解程度, 最终推动高校党建工作的进行。

\section{1 继续发挥微信平台的作用}


利用微信平台的版块设置开展综合性的网络党建建设工作。思政课教师应该在课程建设的基础上不断 调整教学内容, 将最新的内容加入的课堂上, 与学生共建网络微信平台, 在布置课外阅读资料、领导大家 学习党的路线、方针、政策的过程中, 将党建的思想、党的宗旨、作用等内容发送到平台上, 与学生开展 讨论互动, 随时做好信息记录。对于表现优秀, 思想积极要求进步的学生, 要有适当的教育引导措施, 并 及时将学生的进步情况向辅导员汇报沟通, 实现中间的桥梁纽带作用。

思政课教师还可以设计 “学习园地” 版块, 里面包含党课视频、时事政治、大学生对时事的看法, 进 行廉洁教育、警示教育等, 用接地气的语言与清晰的、及时的图片、视频资料为大学生带来耳目一新的感 受, 使学生能在观赏图片、视频的同时学到知识, 提高思想理论水平; 如刚刚召开的十九大, 教师可以及 时将各种关于十九大的报告发送给学生, 并适当的配上自己的导学内容, 使学生关注时事发展, 关注国家 的政策导向和最新思想的主要内容。

“互动交流” 版块中包含留言板和微信群的链接, 留言板是学生党员发表意见和建议的窗口, 学生党 员间也可以利用这个微信群实现互动交流, 分享不同见解。

\section{2 充分利用微博平台的互动功能}

利用微博平台发布党建工作的相关信息。设置大家看时事、支部风采、视频看时事、大家聊党建等话 题。需要指出的是, 这些栏目的设计需要经常跟辅导员取得沟通, 将辅导员的工作内容融入进来, 或者是 将辅导员拉入群里, 使其能参与到微博互动环节中来。如: “大家看时事” 话题每天发布和党建有关的时 事政治以及微博热门社会事件, 从一个大学生的角度发表对这些事件的观点; “支部风采” 话题展示学生 举办、参与的党建活动, 让学生及时更新自己团队活动的信息, 开展网络上的互评互鉴活动; “视频看时 事” 话题可以包含转发有关党建宣传的创意视频、自制党建宣传视频, 以新颖的方式吸引大家的注意力, 帮助大学生提高思想认识; “大家聊党建” 话题可邀请党委老师或在微博具有影响力的研究高校学生党建 的名人与大学生进行互动交流, “话廉洁” 栏目可以通过警示教育宣传片或进行案例分析等形式使学生提 升廉洁意识, 树立正确的人生观、价值观。

\section{3 充分利用知乎平台}

利用知乎平台普及高校大学生党建。在知乎发布和党建有关的问题或者文章, 比如针对 “作为大学生 党员应如何提高思想道德水平” 这类话题, 可以邀请在党建研究领域有影响力的人回答, 带动大家展开讨 论, 借助该平台不断向大家传授党建知识, 帮助大学生了解和认识党的建设及发展过程, 提高大学生对党 建工作的关注度, 同时借鉴大家对党建工作的建议，促进大学生党建工作的发展。

\section{4 丰富党建活动的内容及形式}

传统的党建活动由于内容和空间、活动的类型有所限制, 久之会导致参与者的活动积极性比较低。党 建活动和互联网的结合, 加强了创新性。开设网课以打破地域和空间的限制, 采取实名登陆的方式监督学 生党员的听课质量, 使得大学生党员接受思想教育的方式更加便捷和自由; 建立交流群或论坛进行互动, 促进党员之间、党员与老师之间、党员与培养人之间甚至是跨学校的交流帮助, 起到共同进步的良好作用; 针对某个学习讨论主题, 在网络上搜索影音资料为大家展示, 放在网络平台上共同讨论, 供大家发表意见 和看法, 吸纳交换新的思想; 结合网络进行特别节日的活动开展, 比如在雷锋日倡导大家寻找身边的 “雷 锋式” 的人物, 发表关于他的事迹, 倡导大家向其学习, 通过平凡简单的活动引导学生党员变得更好、学 
到更多。

\section{5 结论}

高校学生党建工作是新时代的重要基层党建工作内容之一, 需要高校各管理部门的高度重视, 需要各 个环节的合作, 更需要辅导员与思政课教师协同起来达到育人的目的。充分利用网络平台完成党建工作也 将成为未来工作的主要平台。

\section{6 基金项目}

（1）大连大学党风廉政建设研究中心课题.全面从严治党视角下大学生廉洁教育研究.2017B4.

（2）2017 年度辽宁省教育科学规划项目, 《提升大学生思政课获得感的路径探讨》, 项目编号：JG17DB038。（3）大 连大学教改项目《史论结合视域下高校“中国化马克思主义理论”课教学话语体系构建研究》.

\section{Acknowledgements}

The subject of the research center of Party style and clean government construction in Dalian University, "Research on the Honesty Education of College Students under the View of Comprehensively Running the Party Strictly", 2017B4.

The scientific planning project of education in Liaoning Province in 2017, "Discussion on the Path of Improving the Sense of Gain of College Students' Ideological and Political Courses", item number: JG17DB038.

Teaching and reform project of Dalian University: "Research on the Construction of the Teaching Discourse System of the "Marxist Theory of China" Course in Colleges and Universities in the View of the Combination of Historical Theory".

\section{参考文献:}

[1] 顾亚竹，徐敏慧．论基于网络平台的高校学生党建工作创新 $[J]$. 教育教学论坛. 2011 年 06 期.

[2] 肖慧. 高校辅导员与思政课教师协同育人的实践与思考 [J]. 学校的党建与思想教育. 2015 年 11 期.

[3] 李春燕. 新媒体时代高校学生党建模式创新的研究 [J]. 辽宁科技学院学报. 2017 年 02 期.

[4] 邓沛栖. 互联网环境下高校党建活力提升的路径 河南科技学院学报 $[J] .2017$ 年第 9 期.

\section{References}

[1] Y.Z.Gu and M.H.Xu: Innovation of Party Building Work of College Students Based on Network Platform[J], Education and Teaching Forum, 2011(06).(In Chinese)

[2] H.Xiao: Practice and Reflection on the Cooperation of College Counselors and Ideological and Political Teachers[J], The Party Building and Ideological Education in Schools, 2015(11).(In Chinese)

[3] C.Y.Li: Research on the Innovation of the Party Building Model of College Students in the New Media Era[J], Journal of Liaoning Institute of Science and Technology, 2017(02).(In Chinese)

[4] P.Q.Deng: The Way of Promoting the Vitality of Party Building in Colleges and Universities under the Internet Environment[J], Journal of Henan Institute of Science and Technology, 2017(09).(In Chinese) 